Meta

Journal des tradlucteurs

Translators' Journal

\title{
Hardware et software : le mot de la fin
}

\section{Paul A. Horguelin}

Volume 14, numéro 2, juin 1969

URI : https://id.erudit.org/iderudit/003102ar

DOI : https://doi.org/10.7202/003102ar

Aller au sommaire du numéro

Éditeur(s)

Les Presses de l'Université de Montréal

ISSN

0026-0452 (imprimé)

1492-1421 (numérique)

Découvrir la revue

Citer cet article

Horguelin, P. A. (1969). Hardware et software : le mot de la fin. Meta, 14(2),

103-104. https://doi.org/10.7202/003102ar d'utilisation que vous pouvez consulter en ligne.

https://apropos.erudit.org/fr/usagers/politique-dutilisation/ 
HARDWARE ET SOFTWARE: LE MOT DE LA FIN

Nos lecteurs se souviendront que nous avons à plusieurs reprises abordé dans notre rubrique le problème de la traduction des termes hardware et software (cf. META, XII, 4: 126; XIII, 2: 73; XIII, 4: 198). Nous croyons pouvoir maintenant clore le débat en publiant une récente fiche du Comité d'étude des termes techniques français.

HardWare-Software - Termes de l'informatique.

DÉfINITIONS: Hardware: équipement matériel et ensemble des appareils formant une calculatrice électronique. Software: en opposition avec le terme précédent, désigne tout ce qui 
vient s'ajouter aux calculatrices électroniques pour permettre, faciliter, assouplir et accélérer le traitement de l'information. Cet ensemble comprend, notamment, les systèmes de programmation.

La paire hardware-software relève d'un double jeu de mots en anglais. L'acception banale de hardware est quincaillerie et c'est par plaisanterie que ce mot est appliqué à la partie matérielle d'une calculatrice. Le mot software fait contraste avec hardware (hard = dur; soft $=$ mou) pour désigner ce qui, en dehors du matériel, est indispensable au fonctionnement de la calculatrice.

TRaductions PRoposées: 1) hardware = matériel; 2) software = périgramme.

Nota - Ces mots ont été retenus à la suite d'une enquête que l'A.F.I.R.O. (Association française d'informatique et de recherche opérationnelle) nous a aidés à mener à bien.

Les deux mots en compétition étaient périgramme et programmaire. Le second, construit à partir de programme et de grammaire, a eu la faveur des spécialistes (75\% des réponses), mais il a fallu l'abandonner, car il ne donnait pas un bon dérivé pour nommer "l'ingénieur de software ». Ce đérivé, qui aurait été programmairien, était vraiment trop proche phonétiquement de grammairien. Périgrammeur, au contraire, est acceptable. Le préfixe « péri » y est gratuit, malgré l'exégèse à laquelle se sont livrées certaines personnes pleines d'esprit.

On peut juger de cet esprit par les doublets qui furent proposés (certains du Canada français) pour conserver le jeu de mots hardware-software: pie matière et dure matière (analogie avec pie-mère); hardoir et softoir, hardonère et softouère (calques phonétiques de l'anglais); hardouère et sophtouaire (sophia = sagesse); mécanaire et programmaire; mécanoïde et programmoïde; matériel et immatériel (mais le software n'est pas immatériel); quincaille et mentaille; logique interne et logique externe.

Paul A. Horguelin 